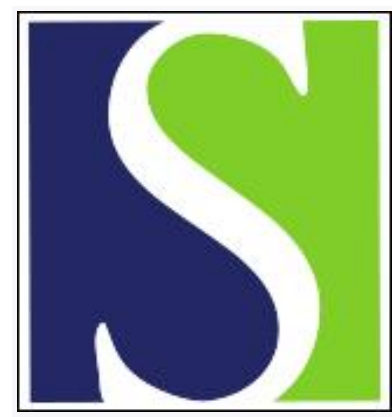

Scand J Work Environ Health 2011;37(6):464-472

https://doi.org/10.5271/sjweh.3182

Published online: 04 Jul 2011, Issue date: Nov 2011

Occupational social class and disability retirement among municipal employees - the contribution of health behaviors and working conditions

by Leinonen T, Pietiläinen O, Laaksonen M, Rahkonen O, Lahelma E, Martikainen $\mathrm{P}$

Affiliation: Department of Social Research, PO Box 18, 00014, University of Helsinki, Finland. taina.leinonen@helsinki.fi

Refers to the following text of the Journal: 1997;23(6):403-413

The following articles refer to this text: $2011 ; 37(6): 451-453$;

2012;38(3):209-217; 2012;38(6):600-603; 2013;39(4):351-360; 2013;39(4):343-350; 2013;39(3):233-240; 2014;40(4):353-360; 2019;45(4):346-355; 2019;45(4):376-385; 2019;45(6):622-630; 2021;47(2):127-135

Key terms: disability pension; disability retirement; Finland; health behavior; job characteristic; lifestyle; mental disorder; musculoskeletal disease; occupational social class; socioeconomic position; work ability; working condition

This article in PubMed: www.ncbi.nlm.nih.gov/pubmed/21727991 


\title{
Occupational social class and disability retirement among municipal employees - the contribution of health behaviors and working conditions
}

\author{
by Taina Leinonen, MSocSc, ${ }^{1}$ Olli Pietiläinen, MSocSc, ${ }^{2}$ Mikko Laaksonen, PhD, ${ }^{2}$ Ossi Rahkonen, PhD, ${ }^{2}$ \\ Eero Lahelma, PhD, ${ }^{2}$ Pekka Martikainen, $P h D^{1}$
}

\begin{abstract}
Leinonen T, Pietiläinen 0, Laaksonen M, Rahkonen 0, Lahelma E, Martikainen P. Occupational social class and disability retirement among municipal employees - the contribution of health behaviors and working conditions. Scand J Work Environ Health. 2011;37(6):464-472. doi:10.5271/sjweh.3182
\end{abstract}

\begin{abstract}
Objectives The mechanisms through which a low socioeconomic position leads to disability retirement are not yet established. We examined, on the one hand, the associations between occupational social class and disability retirement due to all causes, musculoskeletal diseases, and mental disorders and, on the other hand, the contribution of health behaviors and working conditions to these associations.
\end{abstract}

Methods Middle-aged municipal employees from the Helsinki Health Study cohort baseline surveys in 2000-2002 ( $\mathrm{N}=6516)$ were followed up until the end of 2010 for disability retirement. Retirement data were obtained from the registers of the Finnish Centre for Pensions and social class and covariates from the baseline surveys. Social class was categorized into managers and professionals, semi-professionals, routine non-manual employees, and manual workers. Cox regression analysis was used to calculate hazard ratios and their $95 \%$ confidence intervals.

Results The risk of disability retirement was generally higher among those in lower social classes with a strong gradient for all causes, an even stronger gradient for musculoskeletal diseases, and a weaker non-linear association for mental disorders. These associations were largely mediated through physical workload among both women and men and hazardous exposures particularly among men. In mental disorders, job control also mediated the association. Strenuous desktop work and job demands widened the social class differences particularly among men and in mental disorders. The contribution of health behaviors was modest.

Conclusions Improvements particularly in the physical working conditions but also the job control of those in lower social classes are likely to reduce socioeconomic differences in disability retirement.

Key terms disability pension; job characteristic; lifestyle; mental disorder; musculoskeletal disease; socioeconomic position; work ability.

The maintenance of good health, functioning, and working capacity among employees is a key area in preventing early exit from the labor market. In OECD countries, the primary diagnostic causes for disability retirement are musculoskeletal diseases and mental disorders (1). In Finland, for example, each of these accounts for about one third of all diagnoses (2). According to previous studies, a low occupational social class is associated with retirement due to musculoskeletal diseases (3-6) and mental disorders $(3,4)$ as well as with all-cause disability retirement $(3,4,7-12)$. A low social class is often related to unhealthy behaviors and unfavorable working conditions that have also been identified as risk factors for retirement due to disability. Such commonly reported determinants of disability retirement include smoking $(3,5,8,13-15)$, high alcohol consumption (5, $16,17)$, physical inactivity $(5,8,13)$, high relative body weight $(3,5,9,18)$, as well as a range of physical $(5,8$, $12,19-22)$ and psychosocial $(5,8,10-12,21-23)$ factors of working conditions.

There are various ways in which social class may affect health, work ability and subsequent disability retirement. Social class is closely associated with physical and psychosocial working conditions that contribute

1 Population Research Unit, Department of Social Research, University of Helsinki, Helsinki, Finland.

2 Hjelt Institute, Department of Public Health, University of Helsinki, Helsinki, Finland.

Correspondence to: Taina Leinonen, Department of Social Research, PO Box 18, 00014, University of Helsinki, Finland. [E-mail: taina. leinonen@helsinki.fi] 
to working capacity not only through ill-health but also through the job requirements expected from a person considering his or her occupational position $(6,21,22)$. Overall, a high socioeconomic position provides material and non-material resources that promote healthy behaviors and lifestyles and thus helps in avoiding disease and maintaining good health $(24,25)$.

Previous studies from Norway $(5,8)$ and Sweden (3) suggest that health behaviors and working conditions contribute to the association between socioeconomic position and disability retirement, but the magnitudes of the effects have generally been moderate. A recent Norwegian study investigating the mediating effects of particular working conditions also found only modest contributions of job control and physical demands to the association between social class and disability retirement (7). Studies on other domains of health indicate that the associations between a low social class and poor health are partly mediated through a range of physical and psychosocial working conditions including physical demands and exposures (26-29), repetitive work (28), social support (26), job insecurity (28) and job control or its different dimensions (26-31), as well as arrangements related to work schedules (26). Relative body weight may also make a small contribution to the social class gradients in health (28).

Our general aims were to examine (i) whether there are social class differences in disability retirement due to all causes, musculoskeletal diseases, and mental disorders, and (ii) whether health behaviors, relative body weight, work arrangements, and physical and psychosocial working conditions contribute to these associations. We expected that the effects of social class on disability retirement may be mediated through working conditions and health behaviors. Health behaviors, however, often adopted in early life, may alternatively operate as explanatory factors preceding adulthood socioeconomic position and working life.

\section{Methods}

\section{Study population and follow-up}

We used data from the Helsinki Health Study cohort on employees of the City of Helsinki, the largest employer in Finland with approximately 40000 employees (70\% women) within branches comprising general local administration, healthcare, social welfare, education and culture, public transport, and technical and construction services. Baseline survey data were collected during 2000, 2001, and 2002 among employees reaching $40,45,50,55$, or 60 years in each year. A total of 8960 employees responded to the survey ( $80 \%$ women), giving a response rate of $67 \%(32,33)$.
Complete register data on pensions were obtained from the Finnish Centre for Pensions. These data were linked to the baseline survey data via unique personal identification numbers for those respondents who gave written consent to do so (74\%) (33). A total of 6516 employees were included in this study after excluding those (i) not consenting to such data linkage, (ii) in receipt of a pension at baseline (1\%), or (iii) with incomplete information on social class $(0.14 \%)$.

The cohort was followed up for disability retirement from baseline to the end of 2010. In the Finnish retirement scheme, a disability pension is granted based on a medically confirmed diagnosis leading to a reduction in a person's work ability (2). In addition to disability retirement due to any cause, separately we examined retirement in the two largest disease groups, namely, musculoskeletal diseases [International Classification of Diseases (ICD-10) M00-M99] and mental and behavioral disorders (ICD-10 F00-F99).

This study focuses only on disability pensions, but in the Finnish retirement scheme there are also early retirement pensions that are not medically based including unemployment pension at the age of 60 and early old-age pension at the age of 62 years. The lower age limit for the statutory old-age pension is 63 years with the exception of certain occupation-specific retirement ages (2). A participant was censored at the age of 63 years (18\%) as well as in the case of retirement due to reasons other than disability ( $14 \%$ excluding part-time pensions), death ( $1 \%)$, or at the end of $2010(57 \%)$. Death records were obtained from the personnel register of the City of Helsinki and from the registers of the Finnish Centre for Pensions.

\section{Occupational social class}

Occupational social class is a key indicator of socioeconomic position and was categorized using information on occupations from the personnel register of the City of Helsinki for those respondents who gave a written consent for such data linkage (78\%). For the rest, information on occupations was obtained from the survey questionnaire. We included the following hierarchical classes: (i) managers and professionals including those with subordinates and those doing managerial/administrative work as well as other upper non-manual employees doing professional work such as teachers and doctors; (ii) semi-professionals including nurses, foremen, technicians, and other intermediate non-manual employees; (iii) routine non-manual employees including non-professional employees doing, for example, clerical work as well as other lower nonmanual employees, eg, within the social and health services such as child minders and healthcare assistants; and (iv) manual workers including, for example, those in transport work and other technical services as well as in cleaning and canteen work (32). 


\section{Work arrangements}

Information on work contract (ie, working on a permanent or a temporary basis) was derived from the personnel register of the City of Helsinki. The remaining variables used in this study were derived from the baseline survey. Shift work was categorized into those who do shift work (ie, varying shifts at different times of day or night, but not, for example, regular night time work) and those who do not. Overtime work was dichotomized into those who work $>40$ hours per week and those who work $<40$ hours.

\section{Physical working conditions}

Hazardous exposures, physical workload, and desktop work were derived from factor analysis of 18 items of potentially harmful working conditions. The respondents were asked whether they are exposed to each condition and to what extent it bothers them with the response alternatives: "does not exist", "exits but does not bother", "exists and somewhat bothers", and "exists and bothers a lot". We used the items of each factor as sum variables. Hazardous exposures were based on exposure to the following nine items: (i) noise, (ii) vibrations, (iii) dry air, (iv) dust and dirt, (v) dampness and wetness, (vi) mould, (vii) irritating substances such as solvents and gases, and (viii) suboptimal lightning, or (ix) temperature (Cronbach's alpha 0.79). Physical work load was based on six items including (i) uncomfortable working positions, (ii) rotating movements of the back, (iii) repetitive movements, (iv) standing, (v) walking, and (vi) heavy physical work including lifting and carrying (Cronbach's alpha 0.82). Strenuous desktop work was based on adverse consequences of sitting, using the computer, and using the computer mouse (Cronbach's alpha 0.80).

\section{Psychosocial working conditions}

Job control and demands were measured according to the Framingham version of Karasek's job content questionnaire (34) based on sum variables of nine items each (Cronbach's alpha 0.82 and 0.78 ). The respondents were asked whether they agree with statements about their job with response alternatives ranging from "fully agree" to "fully disagree". Job control included statements about the amount of control over work, job variety, and opportunities for the use of skills. Job demands covered pace of work and conflicting demands. Being a victim of workplace bullying (ie, isolation, disregard of one's work, threatening, talking behind one's back, or other forms of mobbing), included four categories: "not at all", "sometimes", "frequently", and "don't know".

\section{Health behaviors}

Smoking was divided into four categories: never smokers, former smokers, current moderate smokers, and current heavy smokers ( $>20$ cigarettes per day). Alcohol consumption was used as a continuous variable on portions of weekly drinks defined as 12 grams of pure alcohol, including various beverages summed up. Physical activity during leisure time or commuting was based on information of the average weekly hours of physical activity in the previous year in four intensity grades ranging from walking to brisk running or other forms of physical activities with equivalent intensities. Total physical activity was calculated by multiplying the time spent in each grade of physical activity with approximate metabolic equivalent index (MET) values estimated for each intensity grade to form a sum variable. Relative body weight or body mass index (BMI) $\left(\mathrm{kg} / \mathrm{m}^{2}\right)$ was based on self-reports on height and weight and used as a continuous variable.

\section{Statistical methods}

We used Cox proportional hazard regression analysis to estimate hazard ratios (HR) and their $95 \%$ confidence intervals $(95 \% \mathrm{CI})$ for disability retirement due to all causes, musculoskeletal diseases, and mental disorders. The contribution of different factors to the association between social class and disability retirement was examined by consecutively including health behaviors and working conditions in the base model. All health behaviors, working conditions, or both of these were also adjusted for simultaneously. Multiple imputation for missing values on the explanatory factors was conducted using the aregImpute function in the Hmisc package (35) for R software. The imputation process was used to create ten imputed datasets, and the data were assumed missing at random. The analyses of all-cause disability retirement were stratified by gender. There was an interaction on the verge of statistical significance $(\mathrm{P}=0.06)$ between gender and social class in the age-adjusted model of disability retirement due to mental disorders, suggesting stronger social class differences among men than women. Women and men were nevertheless pooled in the cause-specific analyses because of the small number of disability retirement events, especially among men, due to musculoskeletal diseases $(\mathrm{N}=38)$ and mental disorders $(\mathrm{N}=39)$.

\section{Results}

During the follow-up, $10 \%$ of women $(\mathrm{N}=512)$ and $8 \%$ of men $(\mathrm{N}=118)$ transferred to disability retirement due to any cause (table 1). Altogether $4 \%$ of employees 
$(\mathrm{N}=270)$ retired due to musculoskeletal diseases and 3\% $(\mathrm{N}=167)$ because of mental disorders.

\section{All-cause disability retirement}

The risk of all-cause disability retirement was higher among those in the lower social classes (table 2). Among women, the gradient was linear with the age-adjusted HR for manual workers being 4.51 (95\% CI 3.34-6.09) as compared to the reference group of managers and professionals. Among men, the association was not fully linear, with the age-adjusted HR being over threefold for both manual $(3.44,95 \%$ CI $2.17-5.46)$ and routine non-manual $(3.32,95 \%$ CI $1.85-5.97)$ classes. Further analyses on the occupational distribution of male routine non-manual employees showed that this non-linear pattern was the result of a deviating occupational group including youth workers and those doing other instructing work within the social welfare branch. Their work cannot be classified as manual despite its low educational requirements typical to many manual occupations. This group constituted $22 \%$ of the male routine non-manual class, but accounted for $44 \%$ of the disability retirement events within this class. Excluding instructors resulted in a fully linear social class gradient also among men (results not shown).

Among women, adjustment for smoking and BMI slightly attenuated the base model social class gradient in all-cause disability retirement (table 2). Adjustment for physical workload contributed most to the association with a $55 \%$ attenuation in the HR for manual workers $\left[\left(\mathrm{HR}_{1}-\mathrm{HR}_{2}\right) /\left(\mathrm{HR}_{1}-1\right) \times 100\right]$. Adjustment for hazardous exposures and job control resulted in more modest attenuations. Desktop work, instead, somewhat widened the social class gradient $(17 \%)$. The HR for manual workers remained strong even after the inclusion of all variables in the model $(2.50,95 \%$ CI $1.71-3.66)$.

Adjustment for BMI slightly attenuated the social class differences also among men, whereas adjustment for smoking had virtually no effect (table 2). Hazardous exposures and physical workload had the strongest contributions to the association with $64 \%$ and $43 \%$ attenuations in the HR for manual workers, respectively. Job control attenuated the association to a smaller extent. Desktop work largely widened the social class differences (47\%). Shift work and job demands contributed to the association only among men. Adjustment for shift work slightly attenuated the social class differences. Adjustment for job demands somewhat widened these differences, and the effect was larger for routine non-manual employees than for manual workers. In the full model, the HR for routine non-manual employees was still $2.61(95 \% \mathrm{CI}$ 1.30-5.21), whereas the corresponding HR for manual workers attenuated to 2.03 (95\% CI 0.99-4.16).

\section{Cause-specific disability retirement}

The social class gradient in disability retirement due to musculoskeletal diseases was considerably stronger than that due to all causes. The base model HR for manual workers was $14.58(95 \%$ CI 8.71-24.43) in the analyses pooling women and men (table 3). Similar factors contributed to the association as in all-cause disability retirement among women with physical workload, hazardous exposures and job control having the largest contributions. The social class differences remained large even after all adjustments (HR 4.92, 95\% CI 2.68-9.02).

In mental disorders, the association between social class and disability retirement was substantially weaker and it followed a non-linear pattern with the base model

Table 1. Distribution of the study population by social class and those being granted a disability pension due to any cause, musculoskeletal diseases, and mental disorders.

\begin{tabular}{|c|c|c|c|c|c|c|c|c|}
\hline & \multirow{2}{*}{\multicolumn{2}{|c|}{ Distribution }} & \multicolumn{6}{|c|}{ Granted a disability pension } \\
\hline & & & \multicolumn{2}{|c|}{ All causes } & \multicolumn{2}{|c|}{ Musculoskeletal diseases } & \multicolumn{2}{|c|}{ Mental disorders } \\
\hline & $\mathrm{N}$ & $\%$ & $\mathrm{~N}$ & $\%$ & $\mathrm{~N}$ & $\%$ & $\mathrm{~N}$ & $\%$ \\
\hline \multicolumn{9}{|l|}{ Women } \\
\hline Managers and professionals & 1462 & 28.6 & 68 & 4.7 & 13 & 1.0 & 29 & 2.0 \\
\hline Semi-professionals & 986 & 19.3 & 84 & 8.5 & 31 & 3.1 & 27 & 2.7 \\
\hline Routine non-manual employees & 2105 & 41.2 & 245 & 11.6 & 113 & 5.4 & 62 & 2.9 \\
\hline Manual workers & 561 & 11.0 & 115 & 20.5 & 74 & 13.2 & 10 & 1.8 \\
\hline Total & 5114 & 100.0 & 512 & 10.0 & 232 & 4.5 & 128 & 2.5 \\
\hline \multicolumn{9}{|l|}{ Men } \\
\hline Managers and professionals & 625 & 44.6 & 30 & 4.8 & 3 & 0.5 & 10 & 1.6 \\
\hline Semi-professionals & 281 & 20.0 & 23 & 8.2 & 7 & 2.5 & 8 & 2.8 \\
\hline Routine non-manual employees & 132 & 9.4 & 18 & 13.6 & 6 & 4.5 & 9 & 6.8 \\
\hline Manual workers & 364 & 26.0 & 47 & 12.9 & 22 & 6.0 & 12 & 3.3 \\
\hline Total & 1402 & 100.0 & 118 & 8.4 & 38 & 2.7 & 39 & 2.8 \\
\hline
\end{tabular}


Table 2. Disability retirement according to social class following adjustment for potential explanatory and mediating factors, women and men. [HR=hazard ratio; $95 \% \mathrm{Cl}=95 \%$ confidence interval.]

\begin{tabular}{|c|c|c|c|c|c|c|c|}
\hline & \multirow{2}{*}{$\begin{array}{c}\text { Managers and } \\
\text { professionals }\end{array}$} & \multicolumn{2}{|c|}{ Semi-professionals } & \multicolumn{2}{|c|}{$\begin{array}{l}\text { Routine non-manual } \\
\text { employees }\end{array}$} & \multicolumn{2}{|c|}{ Manual workers } \\
\hline & & $\mathrm{HR}$ & $95 \% \mathrm{Cl}$ & $H R$ & $95 \% \mathrm{Cl}$ & $\mathrm{HR}$ & $95 \% \mathrm{Cl}$ \\
\hline \multicolumn{8}{|l|}{ Women } \\
\hline Base model a & 1.00 & 2.19 & $1.59-3.01$ & 2.53 & $1.93-3.30$ & 4.51 & $3.34-6.09$ \\
\hline Smoking & 1.00 & 2.16 & $1.57-2.98$ & 2.45 & $1.87-3.21$ & 4.22 & $3.11-5.71$ \\
\hline Alcohol consumption & 1.00 & 2.23 & $1.62-3.08$ & 2.59 & $1.97-3.39$ & 4.62 & $3.42-6.24$ \\
\hline Physical activity & 1.00 & 2.19 & $1.59-3.02$ & 2.55 & $1.95-3.33$ & 4.55 & $3.37-6.14$ \\
\hline Body mass index & 1.00 & 2.13 & $1.55-2.93$ & 2.35 & $1.80-3.08$ & 4.12 & $3.05-5.56$ \\
\hline All health behaviors & 1.00 & 2.12 & $1.54-2.93$ & 2.35 & $1.79-3.10$ & 3.98 & $2.92-5.42$ \\
\hline Shift work & 1.00 & 2.11 & $1.53-2.92$ & 2.43 & $1.85-3.19$ & 4.37 & $3.23-5.91$ \\
\hline Contract type & 1.00 & 2.19 & $1.59-3.01$ & 2.53 & $1.93-3.31$ & 4.53 & $3.35-6.11$ \\
\hline Overtime work & 1.00 & 2.15 & $1.55-2.97$ & 2.49 & $1.90-3.27$ & 4.43 & $3.27-6.02$ \\
\hline Hazardous exposures & 1.00 & 2.13 & $1.54-2.93$ & 2.40 & $1.83-3.14$ & 3.89 & $2.86-5.29$ \\
\hline Physical work load & 1.00 & 1.62 & $1.17-2.25$ & 1.61 & $1.21-2.14$ & 2.58 & $1.87-3.56$ \\
\hline Desktop work & 1.00 & 2.24 & $1.62-3.08$ & 2.70 & $2.05-3.56$ & 5.11 & $3.70-7.07$ \\
\hline Job control & 1.00 & 2.06 & $1.49-2.85$ & 2.18 & $1.64-2.90$ & 3.69 & $2.67-5.10$ \\
\hline Job demands & 1.00 & 2.23 & $1.61-3.07$ & 2.63 & $2.00-3.46$ & 4.68 & $3.46-6.34$ \\
\hline Workplace bullying & 1.00 & 2.16 & $1.57-2.98$ & 2.52 & $1.93-3.30$ & 4.60 & $3.41-6.21$ \\
\hline All working conditions & 1.00 & 1.61 & $1.15-2.26$ & 1.60 & $1.17-2.18$ & 2.76 & $1.91-4.00$ \\
\hline All variables & 1.00 & 1.59 & $1.14-2.23$ & 1.53 & $1.11-2.10$ & 2.50 & $1.71-3.66$ \\
\hline \multicolumn{8}{|l|}{ Men } \\
\hline Base modela & 1.00 & 1.78 & $1.03-3.06$ & 3.32 & $1.85-5.97$ & 3.44 & $2.17-5.46$ \\
\hline Smoking & 1.00 & 1.77 & $1.03-3.05$ & 3.24 & $1.79-5.86$ & 3.35 & $2.10-5.35$ \\
\hline Alcohol consumption & 1.00 & 1.79 & $1.04-3.09$ & 3.38 & $1.88-6.08$ & 3.52 & $2.21-5.61$ \\
\hline Physical activity & 1.00 & 1.77 & $1.03-3.04$ & 3.30 & $1.84-5.93$ & 3.43 & $2.16-5.44$ \\
\hline Body mass index & 1.00 & 1.68 & $0.98-2.90$ & 2.98 & $1.65-5.37$ & 3.19 & $2.01-5.07$ \\
\hline All health behaviors & 1.00 & 1.69 & $0.98-2.92$ & 3.05 & $1.67-5.55$ & 3.14 & $1.95-5.07$ \\
\hline Shift work & 1.00 & 1.74 & $1.01-3.01$ & 3.13 & $1.71-5.73$ & 3.11 & $1.84-5.25$ \\
\hline Contract type & 1.00 & 1.76 & $1.02-3.05$ & 3.31 & $1.84-5.95$ & 3.42 & $2.15-5.45$ \\
\hline Overtime work & 1.00 & 1.75 & $1.01-3.02$ & 3.25 & $1.79-5.88$ & 3.42 & $2.15-5.43$ \\
\hline Hazardous exposures & 1.00 & 1.53 & $0.88-2.65$ & 2.89 & $1.60-5.21$ & 1.89 & $1.10-3.26$ \\
\hline Physical work load & 1.00 & 1.57 & $0.91-2.72$ & 2.64 & $1.45-4.81$ & 2.38 & $1.44-3.94$ \\
\hline Desktop work & 1.00 & 1.88 & $1.09-3.24$ & 4.02 & $2.20-7.35$ & 4.59 & $2.75-7.66$ \\
\hline Job control & 1.00 & 1.66 & $0.96-2.89$ & 3.04 & $1.67-5.55$ & 2.83 & $1.64-4.88$ \\
\hline Job demands & 1.00 & 1.88 & $1.09-3.24$ & 4.06 & $2.21-7.47$ & 3.93 & $2.45-6.32$ \\
\hline Workplace bullying & 1.00 & 1.75 & $1.02-3.02$ & 3.19 & $1.77-5.73$ & 3.44 & $2.17-5.47$ \\
\hline All working conditions & 1.00 & 1.47 & $0.83-2.60$ & 2.92 & $1.48-5.75$ & 2.14 & $1.06-4.32$ \\
\hline All variables & 1.00 & 1.40 & $0.79-2.49$ & 2.61 & $1.30-5.21$ & 2.03 & $0.99-4.16$ \\
\hline
\end{tabular}

adjusted for age

HR being the highest for routine non-manual employees 1.86 (95\% CI 1.24-2.80) and semi-professionals 1.67 (95\% CI 1.06-2.65) (table 4). This non-linear pattern could not be explained by the deviating occupational group of instructors within male routine non-manual employees, and it was found also among women (results not shown). Smoking and BMI slightly attenuated the social class differences as they did for disability retirement due to all causes and musculoskeletal diseases. Adjustment for physical workload and job control attenuated the association most contributing to the HR for all social classes. Hazardous exposures attenuated the HR for manual workers in particular. Desktop work and job demands widened the social class differences, and the effects were larger than what they were in disability retirement due to all causes and musculoskeletal diseases with considerable increases in the HR not only for manual workers ( $168 \%$ and $47 \%$, respectively), but also for routine non-manual employees ( $50 \%$ and $34 \%$, respectively). As a result of these contrasting effects of various working conditions, adjustment for all covariates attenuated the social class differences only to a small extent.

\section{Discussion}

\section{Main results}

Our aim was to examine the association between occupational social class and disability retirement and assess the contribution of health behaviors and working conditions to this association. We found that the risk of disability retirement was considerably higher among 
Table 3. Disability retirement due to musculoskeletal diseases according to social class following adjustment for potential explanatory and mediating factors, pooled results for women and men. [HR=hazard ratio; $95 \% \mathrm{Cl}=95 \%$ confidence interval.]

\begin{tabular}{|c|c|c|c|c|c|c|c|}
\hline & \multirow{2}{*}{$\begin{array}{c}\text { Managers and } \\
\text { professionals } \\
\text { HR }\end{array}$} & \multicolumn{2}{|c|}{ Semi-professionals } & \multicolumn{2}{|c|}{$\begin{array}{l}\text { Routine non-manual } \\
\text { employees }\end{array}$} & \multicolumn{2}{|c|}{ Manual workers } \\
\hline & & $\mathrm{HR}$ & $95 \% \mathrm{Cl}$ & $\mathrm{HR}$ & $95 \% \mathrm{Cl}$ & $\mathrm{HR}$ & $95 \% \mathrm{Cl}$ \\
\hline Base model a & 1.00 & 4.34 & $2.45-7.69$ & 6.15 & $3.68-10.26$ & 14.58 & $8.71-24.43$ \\
\hline Smoking & 1.00 & 4.30 & $2.43-7.62$ & 6.02 & $3.60-10.06$ & 13.87 & $8.25-23.30$ \\
\hline Alcohol consumption & 1.00 & 4.29 & $2.42-7.61$ & 6.06 & $3.63-10.14$ & 14.38 & $8.57-24.14$ \\
\hline Physical activity & 1.00 & 4.34 & $2.45-7.69$ & 6.19 & $3.71-10.34$ & 14.66 & $8.75-24.55$ \\
\hline Body mass index & 1.00 & 4.18 & $2.36-7.41$ & 5.60 & $3.35-9.36$ & 13.01 & $7.76-21.81$ \\
\hline All health behaviors & 1.00 & 4.03 & $2.27-7.15$ & 5.44 & $3.25-9.13$ & 12.39 & 7.33-20.94 \\
\hline Shift work & 1.00 & 4.13 & $2.32-7.33$ & 5.70 & $3.40-9.58$ & 13.53 & $8.03-22.79$ \\
\hline Contract type & 1.00 & 4.31 & $2.43-7.65$ & 6.11 & $3.66-10.21$ & 14.44 & $8.61-24.19$ \\
\hline Overtime work & 1.00 & 4.14 & $2.32-7.36$ & 5.94 & $3.55-9.94$ & 13.92 & $8.28-23.42$ \\
\hline Hazardous exposures & 1.00 & 4.07 & $2.30-7.22$ & 5.46 & $3.27-9.13$ & 10.82 & $6.38-18.34$ \\
\hline Physical work load & 1.00 & 2.91 & $1.63-5.20$ & 3.26 & $1.91-5.55$ & 6.63 & $3.87-11.35$ \\
\hline Desktop work & 1.00 & 4.37 & $2.46-7.76$ & 6.30 & $3.75-10.61$ & 15.31 & $8.88-26.37$ \\
\hline Job control & 1.00 & 4.00 & $2.25-7.10$ & 5.08 & $3.00-8.59$ & 11.12 & $6.46-19.14$ \\
\hline Job demands & 1.00 & 4.40 & $2.48-7.81$ & 6.38 & $3.80-10.71$ & 15.06 & $8.96-25.33$ \\
\hline Workplace bullying & 1.00 & 4.28 & $2.42-7.59$ & 6.10 & $3.65-10.19$ & 14.93 & $8.91-25.02$ \\
\hline All working conditions & 1.00 & 2.62 & $1.45-4.72$ & 2.72 & $1.55-4.77$ & 5.53 & $3.03-10.09$ \\
\hline All variables & 1.00 & 2.51 & $1.39-4.53$ & 2.50 & $1.42-4.40$ & 4.92 & $2.68-9.02$ \\
\hline
\end{tabular}

a Adjusted for age and gender.

those in the lower social classes for all causes and even more so for musculoskeletal diseases, whereas for mental disorders the social class differences were smaller and non-linear. Relative body weight and smoking affected these associations to a very small extent. Physical workload and hazardous exposures seemed to be important mediators between social class and disability retirement regardless of the diagnosis group, whereas the effect of job control was much larger for mental disorders than musculoskeletal diseases. Strenuous desktop work and high job demands, more common among those in higher social classes, widened the social class differences in disability retirement particularly among men and for mental disorders. The contribution of work arrangements was negligible, shift work among men being the only factor with a small mediating effect.

Our results on the more pronounced socioeconomic differences in disability retirement due to musculoskeletal diseases than mental disorders are in line with previous studies $(3,4,22,36)$. However, our finding on the non-linear socioeconomic differences for disability retirement due to mental disorders deviates from previously found linear gradients in older Swedish (3) and Swiss (4) studies with follow-ups mainly in the 1970s and 1980 s as well as in a more recent cross-sectional study from Norway (36). The socioeconomic patterning of disability retirement due to mental disorders needs further investigation especially since the relative importance of mental disorders as a cause for disability retirement has increased in past decades $(37,38)$.

We found that working conditions contribute more to the association between social class and disability retirement than health behaviors, while physical working conditions mediate the association more than psychosocial working conditions. A Danish study showed similar results when investigating the association between social class and long-term sickness absence (39). Our finding on the importance of physical working conditions nevertheless deviates from previous Norwegian results suggesting that, along with job control, physical demands only modestly mediate the association between social class and disability retirement. Studies using health indicators other than disability retirement have reached findings similar to our study: physical demands and exposures (26-29) and job control or its different dimensions (26-31) are important mediators between a low social class and poor health, whereas job demands tend to reinforce the gradients (26-30).

This study, along with previous ones $(3,5,7,8)$, indicates that considerable socioeconomic differences in disability retirement remain even after accounting for working conditions and health behaviors. These may be a result of various factors associated with socioeconomic position as well as health and subsequent disability retirement, such as unmeasured lifestyles and material resources $(24,25)$, earlier circumstances in childhood or adolescence $(40,41)$, as well as lifetime cumulative exposure to adverse conditions including those related to working careers (42).

\section{Methodological considerations}

Although our sample was relatively large, especially for women, the small number of disability retirement 
Table 4. Disability retirement due to mental disorders according to social class following adjustment for potential explanatory and mediating factors, pooled results for women and men. [HR=hazard ratio; $95 \% \mathrm{Cl}=95 \%$ confidence interval.]

\begin{tabular}{|c|c|c|c|c|c|c|c|}
\hline & \multirow{2}{*}{$\begin{array}{c}\text { Managers and } \\
\text { professionals }\end{array}$} & \multicolumn{2}{|c|}{ Semi-professionals } & \multicolumn{2}{|c|}{$\begin{array}{l}\text { Routine non-manual } \\
\text { employees }\end{array}$} & \multicolumn{2}{|c|}{ Manual workers } \\
\hline & & $\mathrm{HR}$ & $95 \% \mathrm{Cl}$ & $\mathrm{HR}$ & $95 \% \mathrm{Cl}$ & $\mathrm{HR}$ & $95 \% \mathrm{Cl}$ \\
\hline Base model a & 1.00 & 1.67 & $1.06-2.65$ & 1.86 & $1.24-2.80$ & 1.38 & $0.82-2.33$ \\
\hline Smoking & 1.00 & 1.67 & $1.06-2.65$ & 1.83 & $1.21-2.75$ & 1.32 & $0.78-2.23$ \\
\hline Alcohol consumption & 1.00 & 1.74 & $1.10-2.76$ & 1.95 & $1.29-2.94$ & 1.45 & $0.86-2.46$ \\
\hline Physical activity & 1.00 & 1.68 & $1.06-2.65$ & 1.87 & $1.25-2.81$ & 1.38 & $0.82-2.34$ \\
\hline Body mass index & 1.00 & 1.64 & $1.04-2.60$ & 1.78 & $1.18-2.68$ & 1.31 & $0.77-2.21$ \\
\hline All health behaviors & 1.00 & 1.69 & $1.07-2.69$ & 1.83 & $1.21-2.78$ & 1.32 & $0.77-2.26$ \\
\hline Shift work & 1.00 & 1.66 & $1.04-2.63$ & 1.83 & $1.20-2.78$ & 1.35 & $0.79-2.31$ \\
\hline Contract type & 1.00 & 1.68 & $1.06-2.66$ & 1.87 & $1.24-2.81$ & 1.39 & $0.82-2.35$ \\
\hline Overtime work & 1.00 & 1.73 & $1.09-2.76$ & 1.92 & $1.27-2.89$ & 1.42 & $0.84-2.41$ \\
\hline Hazardous exposures & 1.00 & 1.60 & $1.01-2.53$ & 1.74 & $1.15-2.62$ & 1.10 & $0.63-1.92$ \\
\hline Physical work load & 1.00 & 1.50 & $0.94-2.39$ & 1.54 & $1.00-2.38$ & 1.09 & $0.63-1.90$ \\
\hline Desktop work & 1.00 & 1.80 & $1.14-2.86$ & 2.29 & $1.51-3.46$ & 2.02 & $1.16-3.51$ \\
\hline Job control & 1.00 & 1.51 & $0.95-2.39$ & 1.46 & $0.94-2.25$ & 0.95 & $0.53-1.70$ \\
\hline Job demands & 1.00 & 1.78 & $1.12-2.82$ & 2.15 & $1.41-3.26$ & 1.56 & $0.92-2.65$ \\
\hline Workplace bullying & 1.00 & 1.65 & $1.05-2.62$ & 1.83 & $1.22-2.75$ & 1.40 & $0.83-2.37$ \\
\hline All working conditions & 1.00 & 1.59 & $0.99-2.57$ & 1.72 & $1.06-2.79$ & 1.29 & $0.67-2.47$ \\
\hline All variables & 1.00 & 1.63 & $1.01-2.64$ & 1.75 & $1.08-2.86$ & 1.32 & $0.68-2.55$ \\
\hline
\end{tabular}

a Adjusted for age and gender.

events resulted in low statistical power in some of the analyses. Furthermore, although we included employees from various employment sectors and from both manual and non-manual occupations, our results were based on middle-aged women and men of a single employer and cannot be generalized to the workforce at large. The prospective study design allows assumptions to be made of the causal mechanisms leading to disability retirement. Information on social class, health behaviors, and working conditions is nevertheless based on the cross-sectional baseline data, and therefore does not account for changes that might have occurred during the follow-up.

Information on social class (partly) and disability retirement (fully) was drawn from registers with no reporting bias, whereas working conditions and health behaviors were based on self-reports. Moreover, physical working conditions not only measured exposure to various conditions, but also the extent to which they were perceived to bother the individual in his or her work. The responses may therefore be subject to reporting bias influenced by health status and work ability. This may overestimate the contribution of physical working conditions as mediators between social class and disability retirement. Non-response to the baseline survey $(33 \%)$ and the exclusion of those who did not give permission to data linkage ( $26 \%$ of respondents) are other sources of potential bias. Non-response analysis of the data indicates that survey participation was somewhat less common among the younger and those in lower socioeconomic positions or with medically confirmed sickness absence. In giving consent to data linkage, the differences between groups were generally in the same direction as those in the survey response, but smaller. Furthermore, even though those with poorer health measured by sickness absence were somewhat underrepresented in the data, the associations between other study variables and participation were generally unaffected by health status (33). Non-response bias is, therefore, unlikely to have had a marked effect on the association between social class and poor health leading to disability retirement.

Some studies (7-10) have investigated the effect of socioeconomic position on disability retirement while adjusting for baseline health status, but whether health is considered to be an explanatory or a mediating factor between these variables is not always specified. In the Finnish pension scheme, a disability pension is only awarded on the basis of a medically confirmed diagnosis leading to a significant reduction in a person's work ability (2). Disability retirement therefore by definition requires a disease and reflects health in itself. Because of this, we expected the effects of socioeconomic, behavioral, and work-related factors on disability retirement to be ultimately mediated through problems of health and work ability and viewed the inclusion of other health variables in the models as unnecessary. Reverse causality cannot, however, be ruled out. Poor health eventually leading to disability retirement may have influenced an individual's prior socioeconomic circumstances, career development, and health behaviors resulting in an overestimation of the importance of working conditions, for example. The selection of employees with health problems from physi- 
cally or mentally strenuous occupations to ones with a less hazardous work environment may, however, also underestimate the mediating effect of working conditions between social class and disability retirement.

\section{Concluding remarks}

We found large social class differences in disability retirement. Our results suggest that unfavorable physical working conditions appear to be the primary reasons for why those in lower social classes have a higher risk of disability retirement, whereas unfavorable psychosocial working conditions and unhealthy behaviors among those in lower social classes contribute less to this difference. A less hazardous work environment not only facilitates the maintenance of good health, but also enables employees to continue working regardless of health problems. Our findings suggest that efforts to reduce socioeconomic differences in disability retirement should focus more on the physical working conditions of low occupational classes. Interventions focused on job control may further reduce these inequalities especially with respect to mental disorders. A reduction in physical demands and exposures as well as better opportunities to control one's job might result in improved employee health and work ability, enabling prolonged working careers particularly among those in lower social classes.

\section{Acknowledgement}

This study was supported by the Academy of Finland [grant numbers 1125733, 1129225, 1121748, 1135630, 1124324, and 1129288], the Finnish Work Environment [grant number 106065], and Doctoral Programs in Public Health.

\section{References}

1. OECD. The OECD "Sickness, Disability and Work" project [Internet]. Paris: OECD; [cited 17 September 2010]. Available from: www.oecd.org/els/disability

2. Finnish Centre for Pensions (ETK), The Social Insurance Institution of Finland (KELA). Statistical yearbook of pensioners in Finland 2009. Helsinki: ETK and KELA; 2010.

3. Månsson N-O, Råstam L, Eriksson K-F, Israelsson B. Socioeconomic inequalities and disability pension in middleaged men. Int J Epidemiol 1998;27:1019-25. doi:10.1093/ ije/27.6.1019.

4. Gubéran E, Usel M. Permanent work incapacity, mortality and survival without work incapacity among occupations and social classes: a cohort study of ageing men in Geneva. Int $\mathrm{J}$ Epidemiol 1998;27:1026-32. doi:10.1093/ije/27.6.1026.

5. Hagen KB, Tambs K, Bjerkedal T. What mediates the inverse association between education and occupational disability from back pain? - A prospective cohort study from the Nord-Trøndelag health study in Norway. Soc Sci Med 2006;63:1267-75. doi:10.1016/j.socscimed.2006.03.041.

6. Holte HH, Tambs K, Bjerkedal T. Manual work as predictor for disability pensioning with osteoarthritis among the employed in Norway 1971-1990. Int J Epidemiol 2000;29:487-94. doi:10.1093/ije/29.3.487.

7. Haukenes I, Mykletun A, Knudsen AK, Hansen HT, Maeland JG. Disability pension by occupational class - the impact of work-related factors: The Hordaland Health Study Cohort. BMC Public Health 2011;11:406. doi:10.1186/1471-2458-11-406.

8. Krokstad S, Johnsen R, Westin S. Social determinants of disability pension: a 10-year follow-up of 62000 people in a Norwegian county population. Int J Epidemiol 2002;31:118391. doi:10.1093/ije/31.6.1183.

9. Månsson N-O, Merlo J. The relation between self-related health, socioeconomic status, body mass index and disability pension among middle-aged men. Eur J Epidemiol 2001;17:65-9. doi:10.1023/A:1010906402079.

10. Claussen B, Dalgard OS. Disability pensioning: the gender divide can be explained by occupation, income, mental distress and health. Scand J Public Health 2009;37:590-7. doi:10.1177/1403494809105795.

11. Laine S, Gimeno D, Virtanen M, Oksanen T, Vahtera J, Elovainio M, et al. Job strain as a predictor of disability pension: the Finnish Public Sector Study. J Epidemiol Community Health 2009;63:24-30. doi:10.1136/jech.2007.071407.

12. Krause N, Lynch J, Kaplan GA, Cohen RD, Goldberg DF, Salonen JT. Predictors of disability retirement. Scand J Work Environ Health 1997;23:403-13.

13. Husemoen LLN, Osler M, Godtfredsen NS, Prescott E. Smoking and subsequent risk of early retirement due to permanent disability. Eur J Public Health 2004;14:86-92. doi:10.1093/eurpub/14.1.86.

14. Claessen H, Arndt V, Drath C, Brenner H. Smoking habits and occupational disability: a cohort study of 14483 construction workers. Occup Environ Med 2010;67:84-90. doi:10.1136/ oem.2009.046318.

15. Koskenvuo K, Broms U, Korhonen T, Laitinen LA, Huunan-Seppälä A, Keistinen T, et al. Smoking strongly predicts disability retirement due to COPD: the Finnish Twin Cohort Study. Eur Respir J 2011;37:26-31. doi:10.1183/09031936.00008910.

16. Månsson N-O, Råstam L, Eriksson K-F, Israelsson B. Alcohol consumption and disability pension among middle-aged men. Ann Epidemiol 1999;9:341-8. doi:10.1016/S10472797(99)00014-9.

17. Upmark M, Möller J, Romelsjö A. Longitudinal, populationbased study of self reported alcohol habits, high levels of sickness absence, and disability pensions. J Epidemiol Community Health 1999;53:223-9. doi:10.1136/ jech.53.4.223. 
18. Karnehed N, Rasmussen F, Kark M. Obesity in young adulthood and later disability pension: a population-based cohort study of 366,929 Swedish men. Scand J Public Health 2007;35:48-54. doi:10.1080/14034940600858524.

19. Karpansalo M, Manninen P, Lakka TA, Kauhanen J, Rauramaa $\mathrm{R}$, Salonen JT. Physical workload and risk of early retirement: prospective population-based study among middle-aged men. J Occup Environ Med 2002;44:930-9. doi:10.1097/00043764200210000-00012.

20. Labriola M, Feveile H, Christensen KB, Strøyer J, Lund T. The impact of ergonomic work environment exposures on the risk of disability pension: prospective results from DWECS/DREAM. Ergonomics 2009;52:1419-22. doi:10.1080/00140130903067771.

21. Stattin M, Järvholm B. Occupation, work environment, and disability pension: a prospective study of construction workers. Scand J Public Health 2005;33:84-90. doi:10.1080/14034940410019208.

22. Blekesaune M, Solem PE. Working conditions and early retirement. A prospective study of retirement behavior. Res Aging 2005;27:3-30. doi:10.1177/0164027504271438.

23. Christensen KB, Feveile H, Labriola M, Lund T. The impact of psychosocial work environment factors on the risk of disability pension in Denmark. Eur J Public Health 2008;18:235-7. doi:10.1093/eurpub/ckm130.

24. Galobardes B, Shaw M, Lawlor DA, Lynch JW, Davey Smith G. Indicators of socioeconomic position (part 1). J Epidemiol Community Health 2006;60:7-12. doi:10.1136/ jech.2004.023531.

25. Laaksonen M, Roos E, Rahkonen O, Martikainen P, Lahelma E. Influence of material and behavioural factors on occupational class differences in health. J Epidemiol Community Health 2005;59:163-9. doi:10.1136/jech.2003.019323.

26. Niedhammer I, Chastang J-F, David S, Kelleher C. The contribution of occupational factors to social inequalities in health: findings from the national French SUMER survey. Soc Sci Med 2008;67:1870-81. doi:10.1016/j. socscimed.2008.09.007.

27. Kaikkonen R, Rahkonen O, Lallukka T, Lahelma E. Physical and psychosocial working conditions as explanations for occupational class inequalities in self-rated health. Eur J Public Health 2009;19:458-63. doi:10.1093/eurpub/ckp095.

28. Borg V, Kristensen TS. Social class and self-rated health: can the gradient be explained by differences in life style or work environment? Soc Sci Med 2000;51:1019-30. doi:10.1016/ S0277-9536(00)00011-3.

29. Schrijvers CTM, van de Mheen HD, Stronks K, Mackenbach JP. Socioeconomic inequalities in health in the working population: the contribution of working conditions. Int $\mathrm{J}$ Epidemiol 1998;27:1011-8. doi:10.1093/ije/27.6.1011.

30. Rahkonen O, Laaksonen M, Martikainen P, Roos E, Lahelma E. Job control, job demands, or social class? The impact of working conditions on the relation between social class and health. J Epidemiol Community Health 2006;60:50-4. doi:10.1136/jech.2005.035758.
31. Andersen I, Burr H, Kristensen TS, Gamborg M, Osler M, Prescott E, et al. Do factors in the psychosocial work environment mediate the effect of socioeconomic position on the risk of myocardial infarction? Study from the Copenhagen Centre for Prospective Population Studies. Occup Environ Med 2004;61:886-92. doi:10.1136/oem.2004.013417.

32. Lahelma E, Martikainen P, Rahkonen O, Roos E, Saastamoinen P. Occupational class inequalities across key domains of health: results from the Helsinki Health Study. Eur J Public Health 2005;15:504-10. doi:10.1093/eurpub/cki022.

33. Laaksonen M, Aittomäki A, Lallukka T, Rahkonen O, Saastamoinen P, Silventoinen K, et al. Register-based study among employees showed small nonparticipation bias in health surveys and check-ups. J Clin Epidemiol 2008;61:900 6. doi:10.1016/j.jclinepi.2007.09.010.

34. Karasek RA. Job content questionnaire and user's guide. Revision 1.1. Lowell, MA: University of Massachusetts, Department of Work Environment; 1985.

35. Alzola CF, Harrell FE. An Introduction to $S$ and the Hmisc and Design Libraries [Internet]. 2006 [cited 9 September 2010]. Available from: http://biostat.mc.vanderbilt.edu/twiki/pub/ Main/RS/sintro.pdf.

36. Bruusgaard D, Smeby L, Claussen B. Education and disability pension: a stronger association than previously found. Scand J Public Health 2010;38:686-90. doi:10.1177/1403494810378916.

37. Järvisalo J, Andersson B, Boedeker W, Houtman I, editors. Mental disorders as a major challenge in prevention of work disability: experiences in Finland, Germany, the Netherlands and Sweden. Helsinki: The Social Insurance Institution of Finland (KELA); 2005. Social security and health reports, no 66.

38. OECD. Transforming disability into ability. Policies to promote work and income security for disabled people. Paris: OECD; 2003.

39. Christensen KB, Labriola M, Lund T, Kivimäki M. Explaining the social gradient in long-term sickness absence: a prospective study of Danish employees. J Epidemiol Community Health. 2008;62:181-3. doi:10.1136/jech.2006.056135.

40. Harkonmäki K, Korkeila K, Vahtera J, Kivimäki M, Suominen S, Sillanmäki L, et al. Childhood adversities as a predictor of disability retirement. J Epidemiol Community Health 2007;61:479-84. doi:10.1136/jech.2006.052670.

41. Upmark M, Lundberg I, Sadigh J, Bigert C. Conditions during childhood and adolescence as explanations of social class differences in disability pension among young men. Scand J Public Health. 2001; 29:96-103. doi:10.1177/140349480102 90020601 .

42. Monden CWS. Current and lifetime exposure to working conditions. Do they explain educational differences in subjective health? Soc Sci Med 2005;60:2465-76. doi:10.1016/j.socscimed.2004.11.017.

Received for publication: 17 March 2011 